\title{
De la necesidad a la acumulación: estrategias residenciales de las familias fundadoras en la periferia de Lima
}

Du besoin

l'accumulation

: les stratégies résidentielles des familles fondatrices

la périphérie de Lima

From necessity to accumulation: the residential strategies of the foundind families in the periphery of Lima

Jimena Ñiquen Castro-Pozo

\section{(apenEdition} Journals

Edición electrónica

URL: http://journals.openedition.org/bifea/8731

DOI: $10.4000 /$ bifea.8731

ISSN: 2076-5827

Editor

Institut Français d'Études Andines

Edición impresa

Fecha de publicación: 8 diciembre 2017

Paginación: 453-469

ISSN: 0303-7495

Referencia electrónica

Jimena Ñiquen Castro-Pozo, « De la necesidad a la acumulación: estrategias residenciales de las familias fundadoras en la periferia de Lima », Bulletin de I'Institut français d'études andines [En línea], 46 (3) | 2017, Publicado el 08 diciembre 2017, consultado el 05 noviembre 2020. URL : http:// journals.openedition.org/bifea/8731 ; DOI : https://doi.org/10.4000/bifea.8731

Les contenus du Bulletin de l'Institut français d'études andines sont mis à disposition selon les termes de la licence Creative Commons Attribution - Pas d'Utilisation Commerciale - Pas de Modification 4.0 International. 


\section{De la necesidad a la acumulación: estrategias residenciales de las familias fundadoras en la periferia de Lima}

Jimena Niquen Castro-Pozo*

\section{Resumen \\ El hábitat popular ha evolucionado de manera significativa durante las últimas décadas. En un nuevo contexto, de crecimiento económico y liberalización del mercado inmobiliario, buscamos aproximarnos a los cambios y continuidades en las estrategias residenciales de las familias fundadoras de barriadas. Detectamos que las familias guiaron el proceso inicial por una lógica de necesidad que, en la actualidad y por la demanda de las segundas generaciones, se ha transformado en una lógica de acumulación. Este cambio está asociado a los valores de uso y de cambio que se otorga al suelo y a la vivienda, así como a la experiencia de las familias. Esto se pudo demostrar a partir del caso de la comunidad urbana autogestionaria de Huaycán, en proceso de urbanización desde hace 33 años. \\ Palabras clave: estrategias residenciales, individualismo metodológico, reproducción de barriadas \\ Du besoin à l'accumulation : les stratégies résidentielles des familles fondatrices à la périphérie de Lima}

\section{Résumé}

L'habitat populaire liménien s'est transformé de manière significative au cours des dernières décennies. Notre objectif est d'aborder les changements et les continuités concernant les stratégies résidentielles des familles fondatrices des barriadas (bidonvilles). Nous avons pu constater que les logiques de besoin présentes durant le processus initial d'occupation se transforment pour les deuxièmes générations qui répondent plutôt à une logique d'accumulation. Ce changement est lié à la valeur d'usage et d'échange donnée au sol et au logement, ainsi qu'à l'expérience des familles. Cela peut être démontré à partir de l'exemple de la communauté urbaine de Huaycán, en processus d'urbanisation depuis 33 ans.

Mots clés : stratégies résidentielles, individualisme méthodologique, reproduction des bidonvilles

* Bachillera en Sociología, Pontificia Universidad Católica del Perú, Av. Universitaria 1801, San Miguel, Lima. E-mail: jimena.niquen@gmail.com 


\title{
From necessity to accumulation: the residential strategies of the foundind families in the periphery of Lima
}

\begin{abstract}
The popular habitat has evolved greatly over the last few decades. In a new context, of economic growth and liberalization of the real-estate market, we seek to characterize the changes and continuity in the strategies of the founding families of the Lima slums. We argue that the families that guided the initial process of development were guided by a logic of necessity while the the second generation is guided by a logic of accumulation. This was demonstrated based on the example of the self-managing urban community of Huaycán, which has been in the process of urbanization for 33 years.
\end{abstract}

Keywords: Residential strategies, methodological individualism, reproduction of slums

\section{RETORNAR A LA CIUDAD POPULAR Y SUS HABITANTES}

La producción de la ciudad popular ha sido un fenómeno ampliamente estudiado en Lima y otras metrópolis de América Latina, pues constituye una de las principales formas de urbanización tras los procesos de migración del campo a la ciudad. Esta ha sido objeto de cambios y continuidades; sin embargo, esta forma de habitar continúa siendo una tendencia en muchas ciudades de la región. Por ello, es pertinente volver a esta línea de investigación en la sociología urbana. Entre 1961 y 1998, la población de estas barriadas se incrementó de un 17\% a un 38\% de la población total de Lima-Callao (Calderón, 2016 [2005]). Además, datos del censo de 2007 dan cuenta del incremento de esta población que llegó a constituir un 48\% del total de los limeños (Calderón, 2016 [2005]: 7).

En este proceso se deben considerar los cambios políticos y económicos que han permitido la continuidad de esta forma de urbanización. Desde la década de 1990, la política económica de desregulación y la promoción de privatizaciones en el Perú permitieron la liberalización del mercado de tierras. Asimismo, Lima se ha visto envuelta en un proceso continuo de crecimiento socioeconómico, a partir del cual se han expandido los sectores medios. Los programas del Poder Ejecutivo han apuntado a satisfacer las demandas de dichos sectores a través de la política de vivienda social.

Por su parte, la producción de la ciudad popular continúa siendo una opción para solucionar la necesidad de vivienda. Sin embargo, en este nuevo contexto, toma características distintas. Primero, la adquisición de terrenos se realiza a través de relaciones de compra y venta y deja de lado la invasión como principal mecanismo de acceso al suelo. Segundo, los asentamientos se sitúan en las «periferias de la periferia», en laderas de cerros alrededor de las primeras ocupaciones. Tercero, la demanda de vivienda proviene de las segundas y terceras generaciones de descendientes de migrantes. Cuarto, los grupos que ocupan las laderas conforman pequeños conjuntos de personas. 
Esta investigación se aproxima a las características actuales de las dinámicas de producción de la ciudad popular que protagonizan las familias residentes. Así, se presentan los cambios en las estrategias de acceso al suelo y a la vivienda de familias que fundaron Huaycán, un proyecto planificado de urbanización en la periferia de la ciudad durante la década de 1980.

Abordamos las trayectorias de las familias fundadoras haciendo énfasis en sus ciclos de vida y las demandas de vivienda que presentan las segundas generaciones. A través de entrevistas a los miembros de las familias se reconstruyeron las estrategias residenciales que han tenido desde el momento inicial de ocupación hasta la actualidad. A partir de ello, observamos que las transformaciones en la estructura social y a nivel subjetivo han promovido variaciones en las estrategias residenciales de las familias. Esta investigación permite ver que los cambios objetivos se relacionan con transformaciones en las lógicas de acción de los actores. La lógica de necesidad que orientó las invasiones se inserta actualmente en un contexto de mercado informal de suelo y es más próxima a una lógica de acumulación. Sin embargo, esto no solo se explica por variables estructurales, sino también por las experiencias que estas familias han acumulado a lo largo de sus trayectorias sobre el funcionamiento del proceso de urbanización en las zonas periféricas de la ciudad.

\section{PROCESOS DE PRODUCCIÓN DE LA CIUDAD POPULAR: CAMBIOS POR ABORDAR}

La alta demanda de vivienda producida por las grandes olas de migración del campo a la ciudad provocó un tipo de urbanización particular en América Latina. Este consistió en la ocupación de terrenos en la periferia de la ciudad por parte de grupos de menores ingresos antes de convertirlos en lugares habitables (Roberts, 1978). Esta forma de urbanización surge frente a la necesidad de un lugar dónde vivir, ante un mercado formal de vivienda que excluye a los sectores de menores ingresos, y un Estado que no veló por una política de vivienda social. Así, se creó una ciudad dual y en conflicto, altamente segregada (Riofrío, 1978; Calderón, 2016 [2005]).

Este proceso de producción del espacio a través de barriadas atravesó varias etapas. La etapa desde la cual partimos (desde 1954 hasta los inicios de la década de 1980) se caracterizó por la ocupación de terrenos eriazos de muy bajo valor económico, fuera del casco urbano de la ciudad. Fue un periodo en el que la ciudad popular se convirtió en un fenómeno trascendente para la urbe (Barreda \& Ramírez Corzo, 2004). Igual de importante fue la organización social entre los fundadores la cual defendía los derechos de vivienda popular, la construcción de un hábitat para aquellos excluidos por la ciudad formal (Calderón, 2016; Riofrío, 1978).

A fines de los años 1980, la literatura describe cómo se han reproducido las barriadas de la década de 1960, aquellas que formaron los «conos». En esta etapa, los que solicitaban vivienda por primera vez eran las segundas generaciones de 
las familias residentes en la ciudad popular (Driant \& Grey, 1988). Los autores trazan el proceso que atravesaron las segundas generaciones para solucionar su necesidad de vivienda pues estaban alojadas en casa de sus padres, incluso años después de formar una familia. Sin embargo, las precarias condiciones de habitabilidad, la evolución del ciclo familiar y las condiciones socioeconómicas dieron pie a la «salida» de algunos miembros de las segundas generaciones, quienes empezaron a formar parte de nuevos asentamientos humanos en zonas periféricas a los lugares de residencia de sus padres.

El proceso de reproducción de las barriadas derivó en la expansión marginal1 (desde fines de la década de 1980 hasta 2004). Este periodo se caracterizó por la disminución de los flujos migratorios hacia la capital y la ocupación de terrenos alrededor de las zonas ocupadas en la etapa anterior que se encontraban en proceso de consolidación. La liberalización del mercado inmobiliario y la promoción de la titulación de tierras (Chion, 2002; Calderón, 2012) incentivaron la expansión de la urbanización en la periferia. Esto ha sido acompañado por procesos de individuación a través de los cuales se incrementaron los comportamientos pragmáticos guiados por intereses privados y se debilitaron la acción colectiva y las relaciones de reciprocidad (Calderón, 2016 [2005]; Martuccelli, 2015). En suma, la producción de la ciudad popular es incentivada por la mercantilización de la vivienda y la ausencia de iniciativas estatales de planificación de la ciudad (Calderón, 2016 [2005]: 18).

Comprender los cambios y continuidades en la estructura social, que da base al crecimiento urbano de la ciudad popular, cobra relevancia si el propósito es comprender el comportamiento de sus habitantes. Siguiendo a Calderón, consideramos que la reproducción de las barriadas o barrios urbano marginales se debe a que «el modo en que se produce la ciudad y se reproducen las clases y los actores, está marcado por su configuración histórica y limitaciones estructurales» (Calderón, 2016 [2005]: 10). Tomando en cuenta esto, nos interesa describir la dinámica de producción de la ciudad popular en la actualidad.

Estudios recientes sobre la evolución de las barriadas apuntan a analizar los procesos de densificación habitacional y de consolidación de los antiguos bolsones (Zolezzi et al., 2005). Estos dan cuenta de la precarización de la habitabilidad generada a falta de un proceso de urbanización como en la autoconstrucción de las viviendas (Ramírez Corzo \& Riofrío, 2006). Por otra parte, se han evidenciado las nuevas formas de expansión a través del mercado informal y del tráfico de lotes (Calderón, 2011). A partir de esto, sabemos cuáles son las estrategias residenciales en la actualidad. En las zonas consolidadas, las transacciones del mercado inmobiliario se realizan a través de alquileres de cuartos o pisos de las viviendas. Por otra parte, en las zonas de expansión, las invasiones ya no son la principal forma de producción del espacio. Las iniciativas de titulación de tierras han generado dinámicas de compra y venta de lotes y de viviendas en las zonas de expansión (Calderón, 2011).

1 Término atribuido por Barreda \& Ramírez Corzo, 2004. 
Si bien la literatura da cuenta de cuáles son las formas de producción de la ciudad y de su estructura urbana, los estudios no explican cómo ni por qué los actores realizan estas transacciones en el mercado de suelo informal. Más allá de vendedores y compradores, consideramos que las familias ocupan un rol protagónico en el proceso. Trazando la trayectoria de estas familias, identificamos cómo los primeros productores de este espacio y sus descendientes han transformado su acción sobre la ciudad popular. La apuesta de esta investigación es incorporar un modelo de análisis poco utilizado en los estudios sobre ciudad popular que hace énfasis en las explicaciones de la acción social. Consideramos que en el marco del mercado de suelo y vivienda dentro de la ciudad popular, las estrategias residenciales nos permiten establecer las conexiones entre la estructura social (i.e. cambios en los marcos culturales, contexto político y económico) y las prácticas y subjetividades de los agentes.

\section{LA CONSTRUCCIÓN DE LA ACCIÓN RACIONAL}

Esta investigación plantea un análisis desde el marco analítico de la acción social, principalmente a partir del individualismo metodológico y la acción racional. A través de este, abordamos las causas que privilegiadas a la hora de explicar las acciones humanas. Estas pueden ser subjetivas (intereses, motivos o impulsos), objetivas (incentivos y recursos), o la combinación de las mismas (Plaza, 2014). En este sentido, permite identificar en qué medida los procesos de construcción de la ciudad popular posibilitan o constriñen las acciones de las familias que estudiamos. Asimismo, analíticamente, podemos distinguir los intereses manifestados en los discursos de las dos generaciones de estas familias, demostrando cambios y continuidades que se revelan en las estrategias residenciales que desarrollan.

Según la literatura sobre estrategias familiares (Moen \& Wethington, 1992), se asume que las familias se plantean acciones a corto y largo plazo con el propósito de consolidar o mejorar su propia situación económica y su estatus. Estas estrategias se encuentran estrechamente relacionadas con un modelo de acción racional a partir del cual planteamos el análisis².

En primer lugar, tal como se ha mencionado, las familias tienen como meta reproducir y mejorar su posición económica y su estatus. En este caso, la vivienda y el suelo constituyen los principales medios para alcanzar este objetivo en tanto poseen un valor de uso y un valor de cambio. La primera está directamente vinculada a la reproducción del ser humano pues en ella se realizan actividades vitales como la alimentación, la crianza, el descanso, etc. (Logan \& Molotch,

2 El modelo analítico se basa en la teoría de James Coleman (1990). El autor plantea el análisis de la acción social en el marco del individualismo metodológico y de la acción racional. Su propuesta se basa en tres componentes a través de los cuales establece conexiones entre la acción y la estructura social. Siguiendo a Coleman, nuestra investigación solo permite identificar cómo la estructura posibilita ciertas acciones y conductas, mas no prueba cómo el conjunto de estas promueve cambios en la estructura misma (el tercer componente). El segundo componente de Coleman consiste en un modelo de análisis basado en los intereses y recursos que un actor posee para tener control o poder sobre algún bien. 
2007; Ward, 2012). El segundo está vinculado al valor de cambio que adquieren los lugares por las relaciones que se mantienen en ellos (servicios, actividad empresarial, etc.) y por la localización que poseen. Así, el suelo se transforma en mercancía y en objeto de transacciones. En la ciudad popular, el valor de uso del suelo informal se produce a partir de la ocupación que le dan los sectores más pobres. Sin embargo, el valor de cambio ha surgido con los procesos de consolidación y expansión y se ha incrementado con los procesos de titulación de tierras (Calderón, 2011).

Como identifica Pedro Abramo (2012) en los países latinoamericanos, la producción de las ciudades resulta del funcionamiento de dos lógicas: la del mercado y la del Estado; pero también de una tercera: la lógica de la necesidad. Esta ha motivado las acciones individuales y colectivas que promovieron las barriadas. En la actualidad, el mercado rige las formas de producción de la ciudad popular. Así, la lógica de necesidad se transforma en una lógica de «mercado informal de suelo», donde la acumulación a partir del valor de cambio del suelo constituye uno de los principales intereses de los actores.

El surgimiento de esta nueva lógica, no solo se debe a los cambios en los incentivos externos (los cambios en el contexto ya mencionados, i.e. la liberalización del mercado de tierras, la titulación y la ausencia de una política de vivienda social y de planificación urbana), sino también a la experiencia de estas familias en el proceso de urbanización. Para complejizar el modelo de acción racional que planteamos para el análisis, sostenemos que la racionalidad con la que las familias ejercen sus estrategias residenciales al ocupar terrenos, se construye a partir de la experiencia de los sujetos en la ciudad popular. Esta brinda recursos importantes (i.e. información y redes sociales) para seguir reproduciendo esta forma de urbanización de manera tal que obtengan mayores beneficios para su reproducción y movilidad social.

Por tanto, sostenemos que los cambios que existen en las estrategias residenciales de las familias fundadoras de Huaycán a lo largo de 33 años implican un giro en la lógica de necesidad del suelo y de la vivienda (demanda de la tenencia de vivienda o de suelo por su valor de uso) hacia una lógica de acumulación (demanda de la tenencia de la vivienda o de suelo recurso cuya transacción otorgará réditos que generen beneficios para la reproducción y la mejora de las condiciones de vida de la familia).

\section{LAS FAMILIAS COMO UNIDAD DE ANÁLISIS}

La presente investigación se planteó como un estudio de caso, el cual permite aproximarnos a relaciones causales complejas (Alexander \& Bennet, 2005). Se escogió a la Comunidad Urbana Autogestionaria de Huaycán, fundada en 1984 como parte de los proyectos planificados de urbanización en zonas de la periferia de Lima durante el gobierno municipal de izquierda de Alfonso Barrantes. Huaycán fue un proyecto planificado cuya ocupación fue dividida en zonas, de la «A» a la «Z», que a su vez poseen ampliaciones (que derivaron de los procesos de expansión no planificada). Las zonas fueron diseñadas en su interior como 
conjuntos de Unidades Comunales de Vivienda (UCV); eran grupos de manzanas cuyo diseño del espacio público fomentaba el encuentro entre vecinos. Cada una está compuesta por 60 lotes de $90 \mathrm{~m}^{2}$ cada uno (Figari, s.f.).

Huaycán fue escogido ya que es poseedor de dos características relevantes para lograr el objetivo de esta investigación. Primero, durante la etapa de ocupación, los grupos que llegaron debían cumplir con ciertas condiciones: no tener vivienda propia, tener pocos recursos económicos y hacer uso residencial del lote que se les otorgaba. Este proceso fue organizado y fiscalizado durante los primeros años de ocupación por las dirigencias y el equipo técnico. A pesar de que esta condición no se cumplió a cabalidad, el no tener otro lugar donde residir da indicios claros sobre la necesidad de las familias de ocupar el lugar. Segundo, al tratarse de una ocupación iniciada años antes de las políticas neoliberales que afectaron el acceso al suelo y a la vivienda, permite identificar cambios en las estrategias residenciales. Actualmente, Huaycán constituye la subzona 3 de la zona 6 del distrito de Ate. Ahí residen aproximadamente 130000 habitantes, el 22\% de la población del distrito, según los datos recogidos por el Programa Barrio Mío. Asimismo, en el Informe del Programa Urbano Integral de Huaycán se estima que 87000 personas residen en zonas formales y 43000 vivirían en las ampliaciones ya descritas. Este crecimiento poblacional ha generado paulatinamente la ocupación de zonas de alto riesgo en las laderas. En las primeras zonas de ocupación, se evidencia un proceso de consolidación no solo manifestado en la construcción de viviendas de material noble, en el acceso a servicios y en la mejora en infraestructura vial, sino también en la presencia de servicios de educación, empleo y comercio.

Se escogió el caso de familias fundadoras de una de las primeras zonas ocupadas en Huaycán. La aproximación a la biografía de las familias permite comprender relaciones a largo plazo y sus cambios en el tiempo (Bertaux \& Delcroix, 2000). Tomando esto en cuenta, elegimos una UCV dentro de la zona E (que surge durante la primera etapa de ocupación) con el fin de aproximarnos a un grupo de familias más homogéneo.

Para abordar este estudio de caso utilizamos una metodología cualitativa basada en entrevistas a profundidad a los miembros de las familias fundadoras, tanto de la primera como de la segunda generación. Ambas generaciones fueron consultadas acerca de las estrategias residenciales que han ejercido a lo largo de los años. Sin embargo, en el análisis nos enfocamos en aquellas estrategias que están directamente relacionadas con el ciclo de vida de la segunda generación y su demanda de vivienda. En el trabajo de campo, corroboramos y comparamos los discursos de varios miembros con el fin de obtener una mirada más completa de la trayectoria de estas familias (Mummert, 2012).

En la UCV 83 de la zona E de Huaycán contactamos a miembros de 10 familias fundadoras y, de cada una, pudimos entrevistar a un miembro de cada generación. Primero entrevistamos a los fundadores para poder rastrear la composición familiar y la trayectoria de la familia. Luego, se conversó con miembros de la segunda generación. Preguntamos, principalmente, acerca de las estrategias residenciales que habían tenido a lo largo de sus vidas y las expectativas que tenían sobre 
sus actuales lugares de residencia. El trabajo de campo se realizó entre abril y junio de 2016. En las visitas a la UCV 83, recogimos el testimonio de 20 vecinos; entrevistamos a la misma cantidad de personas de cada generación.

\section{TRAYECTORIAS FAMILIARES Y ESTRATEGIAS RESIDENCIALES}

El modelo analítico planteado y la información recogida permiten identificar las estrategias residenciales como un proceso relacionado con las trayectorias familiares, los ciclos de vida y los recursos que han adquirido a lo largo del tiempo. En esta investigación se plantea el análisis de dos momentos de estas trayectorias. Primero, el momento inicial de ocupación de Huaycán y, segundo, las estrategias residenciales actuales de las familias.

\section{1. Las familias en la fundación de Huaycán}

Este primer momento en la trayectoria familiar va desde 1984 hasta 1989, tomando en cuenta la llegada a Huaycán y los primeros cinco años de ocupación. En este periodo, empieza la autoconstrucción de viviendas, el trabajo comunal dentro de la UCV y la autoconstrucción y autogestión de equipamientos de salud, educación y comercio. La residencia en el lugar se hizo en un contexto de precariedad. Por ello durante este periodo muchos fundadores decidieron irse. Aproximadamente, el 20\% de los 60 fundadores de la UCV permanece en Huaycán luego de 33 años.

Para explicar por qué solo estas familias fundadoras permanecen en la UCV 83 identificamos tres elementos relevantes. En primer lugar, la característica común a estos miembros fundadores fue la formación de nuevos núcleos familiares antes de llegar a la ocupación o dentro de los primeros cinco años después de la fundación. Otra característica es la posición socioeconómica de los fundadores. La mayoría accedió a la educación secundaria, mientras que un número reducido accedió a la educación superior en institutos técnicos y universidades públicas. Los fundadores accedían a empleos dependientes en el sector industrial y en instituciones educativas como profesores. En el caso de las mujeres fundadoras, dejaron empleos y estudios para hacerse cargo del cuidado de la segunda generación y de la vivienda.

En tercer lugar, tanto en el momento inicial como a lo largo de sus trayectorias, encontraron un espacio de oportunidad en Huaycán. A través del proceso de producción del espacio, accedieron a puestos de trabajo en los primeros equipamientos. El mecanismo más común fue la compra y el alquiler de puestos en el mercado o la creación de pequeños negocios en sus viviendas. Otros modos de beneficiarse del espacio fueron la venta ambulatoria de productos en las avenidas principales y el acceso a puestos de trabajo en las instituciones que se crearon en el lugar, tales como escuelas y hospitales.

Durante este proceso, hubo una sola estrategia residencial: la ocupación organizada de terrenos, acompañada por el equipo técnico. El principal incentivo 
que tuvieron los fundadores al llegar a Huaycán fue la planificación y organización de la ocupación de terrenos para la población con menos recursos. Se consideró que como proyecto planificado, se garantizaba el acceso a la formalización de la propiedad y a los servicios básicos. Por otra parte, se regía bajo estatutos y asambleas comunales. Estos instrumentos delimitaron cuáles eran los requisitos y obligaciones para la persona que solicitaba tener una propiedad en Huaycán. Se dio la prioridad a mujeres madres solteras, núcleos familiares, sin propiedad de terreno o vivienda. Asimismo, se exigió trabajo comunal y permanencia en la ocupación. Ello desincentivó a parte de los fundadores que se fueron durante este primer momento pues no podían cumplir con los requisitos acordados.

A lo largo de sus trayectorias y en relación con sus posiciones socioeconómicas, las familias fundadoras financiaron la construcción y la densificación de sus viviendas. Estos elementos permiten identificar una lógica de necesidad, pues la acción estuvo orientada hacia un uso residencial del espacio por parte de sujetos que no tuvieron suficientes recursos económicos para acceder al mercado formal de suelo; además, sus redes sociales no funcionaron como soporte pues se encontraban insertos en contextos de tugurización y pobreza.

Esta estrategia permitió la obtención de un nuevo bien: la vivienda. Con el paso del tiempo, este bien no solo sería valioso por su uso, sino también por su valor de cambio. Durante el proceso de producción del espacio de oportunidades, los fundadores también aprendieron cómo funcionaba el mercado de suelo urbano. Así, adquirieron conocimiento sobre las localizaciones más favorables de los terrenos y cómo se debe negociar con los dirigentes locales para acceder a favores y beneficios para su propiedad. Estos conocimientos se orientaron hacia el valor de cambio y el beneficio económico. Ello se evidencia en el recuerdo que tienen sobre las decisiones que se tomaron para ubicarse en la zona en que actualmente residen y los aprendizajes que obtuvieron de esta experiencia: saber que la mejor ubicación de un lote depende de su cercanía a la avenida y que los dirigentes tienen poder de decisión e influencia.

Y así, así nos vinimos a la de Dios. Y después... Era para quedarse en la 15 [avenida principal de Huaycán], pero después nos movimos. Había un grupo que nos decían «más arriba está bonito». «Vamos arriba». Como ovejitas nos hemos ido arriba. Nos hubiéramos quedado en la 15 de julio (risas). Y ya pues, nos vinimos más arriba. Porque... Nuestro sitio era la 15 de julio. En la misma 15 de julio era porque los que se quedaron ahora tienen casa en la misma 15. En la misma 15 tienen [negocios]... Los demás se arrepienten porque ahí se quedaron los valientes [era difícil ocupar ahí]. Pero subieron acá arriba a la zona E, a la 83. Así fue. Nos hubiéramos quedado en la 15 de julio. Cuando mi papá ve, se arrepiente. Da risa. «Hubiéramos cogido terreno. En otro sitio hubiéramos vivido [fuera de Huaycán]», dice (risas) (Mujer, 38 años, segunda generación). 


\section{2. Las familias, 33 años después}

Las estrategias residenciales de las familias fundadoras en la actualidad son incentivadas por el surgimiento de nuevos núcleos familiares y por un contexto diferente en el que el mercado informal de suelo guía la reproducción de la ciudad popular. A continuación, se describirán las estrategias realizadas hasta junio de 2016. Estas dan cuenta de un proceso directamente relacionado con la trayectoria familiar, el mercado de suelo informal y los diversos recursos que estas familias poseen. Asimismo, el análisis también permite identificar transformaciones en la lógica que impulsa estas estrategias, cuyo objetivo se orienta hacia la acumulación de capital económico a partir del valor de cambio del suelo urbano.

Actualmente, la composición de las familias es la siguiente. Los fundadores tienen entre 50 y 65 años. A lo largo de sus trayectorias, han trabajado de manera dependiente e independiente en condiciones de inestabilidad y precariedad laboral. No obstante, ello permitió uno de los cambios al interior de las familias, que la mayoría de los miembros de la segunda generación acceda a la educación superior en institutos y universidades nacionales. En consecuencia, hubo una relativa mejora en la posición socioeconómica de las familias estudiadas.

La segunda generación tiene entre 20 y 38 años de edad y sus trayectorias son más heterogéneas. Entre los mayores, identificamos dos caminos: aquellos que culminaron estudios superiores y actualmente se emplean de acuerdo a sus estudios, y los que no lo hicieron, ya sea por los escasos recursos de la familia y/o porque tuvieron hijos. Los últimos son quienes se encuentran en una situación económica más inestable, mientras que los más jóvenes estudian o estudian y trabajan.

A partir del análisis de las trayectorias familiares, se han identificado las secuencias de estrategias residenciales más recurrentes, las que se relacionan estrechamente con el ciclo de vida de estas familias. A continuación se presentan estos procesos.

\section{2. 1. Permanencia en la casa de origen}

Constituye la primera estrategia dentro del proceso. La segunda generación nace y reside en la vivienda de sus padres durante las primeras etapas de su ciclo de vida. Es la principal tendencia; constituye un momento de transición en la trayectoria de las familias pues se convierte en una forma de ahorro económico para la segunda generación, ya que comparten gastos y esfuerzos con sus padres. Este momento inicial implica la construcción de nuevos pisos de la vivienda de los fundadores. El objetivo es proveer mayor espacio habitable a su familia $y$, a largo plazo, generar un bien más rentable en caso de venta o alquiler de la vivienda. Este proceso es heterogéneo ya que las modificaciones en la vivienda dependen de los recursos económicos de las familias y de las necesidades que se presenten, que consisten en la construcción de cuartos propios para los miembros de la familia y mayor espacio cuando surgen nuevos miembros de la segunda o tercera generación. Durante este periodo de espera, algunas familias adquieren 
lotes en zonas de expansión bajo una lógica de prevención. Desarrollaremos este punto en la descripción de los demás procesos.

Esta es una etapa de espera ante la existencia de detonantes. Se identificaron dos: el surgimiento de un nuevo núcleo familiar y un eventual conflicto familiar que dificulte la convivencia. Por ello, jóvenes solteros y sin hijos son quienes mayoritariamente permanecen en la vivienda de sus padres. Este grupo se dedica a estudiar o trabajar mientras ahorra dinero y/o espera el surgimiento de un elemento que les incite a independizarse.

Después, junto con la aparición de alguno de estos dos motivos, se identifican dos posibles estrategias residenciales: la mudanza a una zona consolidada (en Huaycán o Lima Este) o la mudanza a una zona de expansión. En general, si una familia tiene hijos que permanecen en la casa de los fundadores y tienen al menos un hijo viviendo en zona consolidada, no es posible que otro hijo resida en alguna zona de expansión. Esta disparidad se debe principalmente a diferencias entre las familias fundadoras en cuanto a los recursos económicos que poseen, lo cual se manifiesta en el acceso a la educación superior y en una mayor estabilidad económica de la primera generación en relación a la de sus vecinos.

\section{2. 2. Mudanza a zonas consolidadas de Huaycán y Lima Este}

Esta es la estrategia residencial deseada porque es valorada positivamente por el confort que puede generar, los beneficios de localización y la mejora del estatus de la familia. Las familias que realizan esta acción son aquellas que cuentan con mayores recursos económicos, obtenidos a lo largo de la trayectoria de la primera y segunda generación, con trabajos estables y educación superior, respectivamente. Sin embargo, esta estrategia es la menos común. En ese sentido, quienes la utilizan han gastado parte de su capital acumulado durante el primer momento de este proceso; hasta el momento, son la minoría. Así, aquellos que siguieron esa trayectoria ya no acumulan, sino buscan estabilizar y reproducir su posición social en su nueva residencia.

\section{2. 3. Mudanza a zonas de expansión de Huaycán}

Esta estrategia se ejerce cuando la familia posee menos recursos económicos. Ante ello, regresar a zonas menos confortables, con mala localización e infraestructura, se considera una posibilidad razonable frente a la demanda de vivienda y sus bajos ingresos. Si bien implica una inversión, es una estrategia factible por dos tipos de recursos que las familias fundadoras poseen: redes sociales y conocimiento sobre las dinámicas urbanas en Huaycán, principalmente el funcionamiento de su mercado informal de suelo. Todo ello se adquirió gracias a la experiencia acumulada a lo largo de los años en Huaycán. Además, es viable ya que pueden recurrir a la vivienda de la primera generación, ubicada en la zona consolidada, para poder beneficiar del apoyo familiar y tener acceso a servicios básicos y a algunas comodidades. 
Esta estrategia se origina principalmente con el uso de lotes que fueron adquiridos durante la primera etapa del proceso. En ese sentido, responde a la necesidad de vivienda de la segunda generación. Sin embargo, a partir del análisis detallado de la estrategia, se identifica la nueva lógica que impulsa los actuales procesos de adquisición de lotes.

\section{EL PASO DE LA NECESIDAD A LA ACUMULACIÓN: LA LÓGICA DEL POR SI ACASO}

El proceso de mudanza a la zona de expansión pasa por dos etapas distintas cuyos análisis permiten identificar la lógica que motiva la ejecución de la estrategia. Estas son el acceso al terreno, el cual se realiza en la primera etapa del proceso descrito anteriormente, y el uso que se le da al mismo. En cada una se visibilizarán los recursos e incentivos que tuvieron las familias en cada momento.

\section{1. La adquisición del lote}

Los miembros de la primera generación tomaron iniciativa en la adquisición del lote. Se hicieron cargo de la transacción y recibieron ayuda de sus hijos en el proceso. Si bien la nueva forma de urbanización se caracteriza por transacciones de compra y venta, y por la asociación de grupos reducidos de personas, en el proceso existen requisitos impuestos por las asociaciones de vivienda y la municipalidad. Estos se refieren a la zonificación del predio y a la posesión del mismo a nombre de sujetos sin alguna otra propiedad. Por ello, los terrenos se adquieren a nombre de los hijos. Además, como familias fundadoras, los miembros de la primera generación tuvieron recursos que facilitaron el proceso. En la siguiente cita, una fundadora recuerda cómo se decidió a adquirir el terreno. Hace referencia a la información que posee sobre el proceso de producción del espacio:

Hace tiempo fue... Más de diez años ya. Varios vecinos de acá cogimos en la Z. La vecina de la casa de la esquina me pasó la voz. Mi hija ya estaba con su pareja, esperando al segundo. Ella me avisó que estaban inscribiendo para coger terrenos de $300 \mathrm{~m}^{2}$ allá arriba. Ah... sí eran buenos porque cuando fuimos a ver estaba planito y era en buena zona. Nos dijeron que por ahí iba a continuar la avenida. Mi hija vive en la misma avenida, al inicio de la Z, ahí se puede poner negocio. Al frente hay una fábrica. (...). Yo no estaba segura. Decía: «ipara qué ir a estar pendiente allá arriba? Ya tuve suficiente para construir esta casa». Pero mi amiga me dijo que tuviera por si acaso pasara algo, que pensara en mis hijos. Acepté (Mujer, 56 años, primera generación).

Las formas de acción sobre el mercado informal de suelo urbano se refuerzan con la experiencia previa de estas familias. Así, se presentan situaciones en las que se buscan terrenos en futuras avenidas. Esta situación no se consideró en el momento de la ocupación de la UCV 83. Asimismo, se sabe qué tipo de terreno 
es adecuado para la construcción de una vivienda. En ese sentido el hecho que sea «planito» es importante para los padres.

Por otro lado, las redes sociales constituyen el otro recurso que poseen las familias fundadoras. El vínculo con dirigentes y antiguos vecinos resulta beneficioso por la información que otorgan acerca de terrenos en proceso de ocupación. Mantener buenas relaciones con dirigentes resulta también útil durante el proceso de adquisición porque facilita el cumplimiento de requisitos ante el gobierno local. En una conversación registrada durante el trabajo de campo, un miembro de la segunda generación y un antiguo dirigente, vinculado al gobierno central de Huaycán, recordaban cómo el dirigente le había pasado la voz previamente a la visita de lotes en una de las áreas de expansión en la que se revisó que los titulares hicieran uso residencial del predio y que tuvieran sus «papeles en regla».

Por último, los miembros de la misma familia forman parte de estas redes sociales y actúan como respaldo en el proceso de ocupación. Entre los miembros, tanto de primera como de segunda generación, se turnan para proteger los lotes o avanzar arreglos en las viviendas. Mientras uno se encarga de esa tarea, otros colaboran para cuidar la tercera generación. Debido a la corta distancia entre la zona consolidada y la zona de expansión, la dinámica es más sencilla pues se establece una complementariedad entre las propiedades.

La adquisición de estas propiedades sirve para prevenir. Las familias velan por un respaldo económico ante situaciones de contingencia que pudieran afectar a la familia. Consideramos que ello corresponde a un cambio en la lógica de necesidad a una de acumulación. Sin embargo, tal como se evidencia, no se trata de un afán de acumular tierras, sino de utilizarlas como bienes económicos cuando fuese necesario.

\section{2. Usos de los lotes en la zona de expansión}

El análisis de esta etapa presenta tres lógicas de acción sobre el suelo urbano, de acumulación, de necesidad y la combinación de ambas. Las variables que permiten realizar estas distinciones parten de las siguientes preguntas: ¿qué miembros de las familias fundadoras hacen uso del predio?, ¿cuál es el uso que se le otorga? y ¿cuál es el grado de inmediatez con el que se hace uso del lote? (cuadro 1).

Cuadro 1 - Lógicas y formas de uso de lotes

\begin{tabular}{|l|l|l|l|}
\hline & $\begin{array}{l}\text { Uso por } \\
\text { acumulación }\end{array}$ & Uso por necesidad & $\begin{array}{l}\text { Uso por necesidad y } \\
\text { acumulación }\end{array}$ \\
\hline $\begin{array}{l}\text { Miembro de la } \\
\text { familia }\end{array}$ & $\begin{array}{l}\text { Primera } \\
\text { generación }\end{array}$ & Segunda generación & Segunda generación \\
\hline Tipo de uso & Mixto & Residencial & Residencial \\
\hline $\begin{array}{l}\text { Grado de } \\
\text { inmediatez }\end{array}$ & Inmediato & Inmediato & Tardío \\
\hline
\end{tabular}

Fuente: Trabajo de campo realizado entre abril y junio de 2016. Elaboración propia 
El uso por acumulación hace referencia a un lote que funciona como una extensión de la propiedad ubicada en la zona consolidada. Los lotes se usan para la crianza de animales o para la implementación de pequeños negocios, lo cual es permitido por la zonificación. Además, el uso es inmediato ya que se exige cumplir con los requisitos de ocupación, y es a su vez una forma de cuidar los lotes. Así, los fundadores aprovechan los lotes para actividades que gustarían realizar en sus viviendas, pero no pueden hacer por falta de espacio. Estos predios se mantienen como mercancía de la familia. Sin embargo, el título pertenece a un hijo. Queda la posibilidad de hacer uso residencial del lote o de venderlo, eventualmente.

El uso por necesidad y aquel que se inserta entre las dos lógicas están relacionados con una etapa de independización de la segunda generación respecto de sus padres. El primero se refiere a aquellas familias donde alguno de sus miembros de la segunda generación ejerce la ocupación inmediata del predio. Las causas de esta situación son conflictos intrafamiliares, principalmente. En ese sentido, su acción es guiada por una lógica de necesidad, similar a la de sus padres en la etapa de ocupación de las zonas consolidadas.

El segundo, el uso por necesidad y acumulación, es llevado a cabo por miembros de la segunda generación que esperaron a que el lote estuviese construido con material noble y que contara con servicios básicos para residir ahí. En este caso, la mudanza hacia el lote no necesariamente corresponde a la expulsión de la casa de origen por conflictos familiares o por el hacinamiento. Se da por la búsqueda de independencia. Esta acción también es incentivada por las dinámicas de alquiler en la zona consolidada pues los cuartos antes utilizados pueden generar ingresos a la familia, principalmente a la primera generación, lo cual también demuestra una intención de acumulación. Además, esta dinámica tiende a desencadenar la mudanza de la primera generación a la zona de expansión por motivos de cuidado de su salud y el apego a sus hijos. En la siguiente cita se ilustra la ejecución de esta estrategia:

Tampoco me vine a vivir acá [zona en expansión]. Mi suegra, que era bien linda, había puesto su tienda ahí y yo me fui pa' abajo. Yo me seguía con mi mamá hasta casi... Desde el 2000, ¿cuántos años han pasado? En el 2012 casi he venido acá pues. Hace doce años. Yo vine cuando ya había luz y todo, sólo faltaba la pista, ya después ya. Ya tenía todo, ya había todo, ya. Porque no ves que Alan [García] entró en el 2011 y él dio agua pa' todos... A todos les dieron agua. Ya por eso cuando ya había agua, luz, ya todos subimos. Ya para qué si hay de todo acá. Abajo que mi mamá lo alquile para ella. Así hicimos (Mujer, 38 años, segunda generación).

\section{LAS EXPECTATIVAS DE LAS FAMILIAS SOBRE SUS ESTRATEGIAS RESIDENCIALES}

Hemos descrito los usos que se otorgan a los lotes en zonas de expansión. Ellos dan cuenta de prácticas que lindan entre dos lógicas: necesidad y acumulación. Además, se evidencia que el alquiler en la zona consolidada y la herencia de la 
vivienda funcionan como respaldo para los núcleos familiares que ahora residen en las zonas de expansión. El análisis de las expectativas permite ver que las proyecciones de los miembros de la segunda generación implican acciones sobre el predio en el que residen y sobre el de sus padres.

La expectativa de los residentes de las zonas de expansión es el retorno a las zonas consolidadas de Huaycán. Ello no implica un retorno a la misma vivienda de los padres. En ese sentido, su salida hacia la periferia es claramente transitoria:

E: ¿Qué expectativas tienes sobre tu lugar de residencia? De acá a 5 años, 10 años.

L: De acá a 10 años, de acá a 10 años, sí. Yo voy a vender mi casa y me voy a ir.

E: ¿A dónde te vas a ir?

L: A buscar un sitio por abajo, ¿no te digo? Eso es lo que yo estoy pensando, lo que yo tengo en proyecto. En 10 años, los vendo los dos lotes y me voy a buscar casa por abajo. Ya me encontraré un lote, aunque sea el de Juan [vecino de la UCV 83 de la zona E] (risas).

Ello se refuerza con la demanda de viviendas en las zonas de expansión y al incremento de su valor de cambio causado por las inversiones realizadas a través de la autoconstrucción y de programas de vivienda como Techo Propio:

Acá es la mitad, casi [del precio de la vivienda en zona consolidada]. Pero hay gente que viene a buscar casas, ah, lotes. Sí, vienen. Sí, varias veces quieren comprar, alquilar, porque por abajo está caro (...). La señora quiere venderlo a 10 mil dólares.

El deseo de regresar a las zonas consolidadas está relacionado con una percepción del lugar como más seguro, más limpio y más bonito. Dichas características son contrarias a la valorización que se tiene de las zonas de expansión. Las segundas generaciones buscan que sus hijos vivan en un mejor lugar:

Ella va a traer a sus amiguitas, va a querer algo grande. Me va a decir: «Papá, van a subir hasta el cerro, hasta arriba». Por eso también nosotros estamos pensando en otro lado (...). En la casa de mi suegra, cada hermano tiene un piso, por eso, mi hija como ha escuchado eso de repente ella también está viendo esa manera: «ya que mi mamá se vaya pa' arriba, que me dé a mí (Hombre, 36 años, segunda generación).

Si bien no podemos predecir si las expectativas se llevarán a cabo, se sabe que sus estrategias se guían por esa idea. Sabemos que la transacción no permitiría adquirir un predio en las zonas más consolidadas, pero la herencia o el ingreso por el alquiler de la casa de sus padres podrían ser recursos importantes para sus trayectorias residenciales. Investigaciones longitudinales podrían explicar si efectivamente fueron inversiones transitorias y cómo los procesos estructurales afectan dichas estrategias, pues hasta el momento en ninguna de las familias encuestadas se ha dado el caso del uso de vivienda como herencia. 


\section{REFLEXIONES FINALES}

La investigación logra mostrar cómo las familias fundadoras de la ciudad popular reproducen las formas de consolidación y expansión a través de sus estrategias residenciales. La trayectoria de las familias permite entender sus formas de acción en este nuevo contexto. Así, la descripción de estas estrategias residenciales muestra los comportamientos de un actor específico y, a su vez, invita a pensar los efectos que la suma de sus estrategias a la de otros actores tiene sobre la reproducción de la ciudad popular.

Así, se demuestra que la transformación de sus acciones está guiada por una estructura política y económica que permite adquirir réditos a partir de lotes en zonas de expansión. A través del análisis de estas estrategias a lo largo del tiempo, podemos identificar cómo la necesidad de vivienda que buscaron satisfacer los miembros fundadores ya no es el principal motivo por el cual se adquieren lotes o viviendas. Actualmente, la posesión de estos funciona como un soporte económico para estas familias. En ese sentido, las constantes experiencias de inestabilidad de las familias dan pie a que se busquen recursos para garantizar su estabilidad y mejora. Este elemento subjetivo permite comprender cómo el mercado ha dado paso a la especulación sobre el suelo y la vivienda por parte de actores que, si bien han tenido trayectorias de movilidad social, conviven con una alta percepción de vulnerabilidad. Así, el suelo representa un recurso que ayuda a prevenir situaciones que pongan en riesgo la reproducción social de las familias. Por otra parte, el análisis de los componentes de la estrategia permite identificar los recursos que facilitan el acceso y el uso de los lotes en zonas de expansión y reducen los costos en comparación con las primeras ocupaciones. Se identifica pues que el conocimiento sobre el proceso de urbanización y las redes sociales constituyen recursos valiosos en la ciudad popular. En suma, el apoyo familiar y el respaldo de la propiedad familiar en la zona consolidada dan cuenta de que la ayuda entre miembros de las dos generaciones constituye un elemento vital para la estabilidad y mejora económica de la familia.

Tomando en cuenta lo anterior, surgen preguntas sobre los verdaderos efectos de estas estrategias sobre procesos de movilidad social, tanto ascendentes como descendentes. Por otro lado, cuestiona si la lógica de acumulación genera descuido sobre la sostenibilidad y la prevención de riesgo en las zonas de expansión.

\section{Referencias citadas}

ABRAMO, P., 2012 - La ciudad com-fusa: mercado y producción de la estructura urbana en las grandes metrópolis latinoamericanas. EURE Revista latinoamericana de estudios urbano regionales, 38 (114): 35-69.

ALEXANDER, G. \& BENNET, A., 2005 - Case studies and theory development in the social sciences; Cambridge: Harvard University Press. 
BARRERA, J. \& RAMÍREZ CORZO, D., 2004 - Lima: Consolidación y expansión de una ciudad popular. In: Perú Hoy: las ciudades en el Perú: 201-218; Lima: DESCO.

BERTAUX, D. \& DELCROIX, C., 2000-Case histories of families and social processes: enriching sociology. In: The Turn To Biographical Methods in Social Science. Comparative Issues and Examples (Chamberleyne et al., eds.): 71-89; Londres: Routledge.

CALDERÓN, J., 2012 - Las políticas de vivienda social: entre la vivienda nueva y la construcción en sitio propio. Revista de sociología Universidad Nacional Mayor de San Marcos, 18 (22): 207-234.

CALDERÓN, J., 2016 [2005] - La ciudad ilegal. Lima en el siglo XX, 398 pp.; Lima: Punto Cardinal.

CHION, M., 2002 - Dimensión metropolitana de la globalización: Lima a finales del siglo XX. EURE Revista Latinoamericana de Estudios Urbano Regionales, 28 (85), diciembre: 71-85.

COLEMAN, J., 1990 - Foundations of Social Theory, 993 pp.; Cambridge: The Belknap Press of Harvard University Press.

DRIANT, J.-C. \& GREY, C., 1988 - Acceso a la vivienda para la segunda generación de las barriadas de Lima. Bulletin de I'Institut Français d'Études Andines, 17 (1): 19-36.

FIGARI, E., (s.f.) - Huaycán: Una experiencia de urbanismo popular. Huaca, 1: 26-30.

LOGAN, J. \& MOLOTCH, H., 2007 - Urban fortunes. The political economy of place, xxix + 383 pp.; Berkeley: University of California Press.

MARTUCCELLI, D., 2015 - Lima y sus arenas. Poderes sociales y jerarquías culturales, 326 рp.; Lima: Cauces Editores.

MOEN, P. \& WETHINGTON, E., 1992 - The Concept of Familiy Adaptive Strategies. Annual Review of Sociology, 18: 233-251.

MUMMERT, G., 2012 - Pensando las familias transnacionales desde los relatos de vida: análisis longitudinal de la convivencia intergeneracional. In: Métodos cualitativos y su aplicación empírica. Por los caminos de la investigación sobre migración internacional (M. Ariza \& L. Velasco, eds.): 151-184; México: Universidad Nacional Autónoma de México (UNAM).

PLAZA, O., 2014 - Teoría Sociológica. Enfoques diversos, fundamentos comunes, 268 pp.; Lima: Fondo Editorial Pontifica Universidad Católica del Perú.

RAMÍREZ CORZO, D. \& RIOFRÍO, G., 2006 - Formalización de la propiedad y mejoramiento de barrios: bien legal, bien marginal, 64 pp.; Lima: DESCO Centro de Estudios y Promoción del Desarrollo.

RIOFRÍO, G., 1978 - Se busca terreno para próxima barriada. Espacios disponibles en Lima 1940-1978-1990, xiv + 171 pp.; Lima: DESCO Centro de Estudios y Promoción del Desarrollo.

ROBERTS, B., 1978 - Cities of Peasants: The Political Economy of Urbanization in the Third World, vi +207 pp.; Beverly Hills: Sage Publications.

WARD, P., 2012 - "A Patrimony for the Children": Low-Income Homeownership and Housing (Im)Mobility in Latin American Cities. Annals of the Association of American Geographers, 102 (6): 1489-1510.

ZOLEZZI, M., TOKESHI, J. \& NORIEGA, C., 2005 - Densificación Habitacional: Una propuesta de crecimiento para la ciudad popular, 138 pp.; Lima: DESCO Centro de Estudios y Promoción del Desarrollo. 